\title{
DISKRIMINASI FEMINIS
}

\section{THIOFANI FREDELINE}

\section{INSTITUT AGAMA KRISTEN NEGERI TORAJA}

\author{
thiofanifredeline16@gmail.com
}

\begin{abstract}
Abstrak: The issue of differences in treatment or gender inequality is still an interesting discussion. These days we can still see the practice of gender inequality in some space which we are not aware of because it is soft power. Feminism as a framework and study of social life is able to make us aware of the reality of gender inequality as weel as offer solutions to human problems through a balanced assessment of the individuality of women and emphasizes that we treat fellow human beings as creatures, where we should respect gender differences and treat them fairly.
\end{abstract}

Abstrak: Isu perbedaan perlakuan atau ketidaksetaraan gender masih menjadi perbincangan menarik. Hari-hari ini masih dapat kita lihat praksis ketidaksetaraan gender di sebagian ruang yang sebenarnya tidak di sadari sebab bersifat soft power. Feminisme sebagai kerangka kerja dan studi kehidupan sosial mampu menyadarkan kita tentang realitas ketidaksetaraan gender serta menawarkan solusi dari masalah kemanusiaan melalui keseimbangan penilaian pada pria dan wanita serta menegaskan bahwa memperlakukan sesama manusia sebagai makhluk ciptaan, dimana kita seharusnya menghormati perbedaan gender dan memperlakukannya secara adil.

\section{Pendahuluan:}

Feminisme sebagai suatu gerakan dari Barat yang hampir di seluruh dunia menggunakannya sebagai suatu acuan untuk menjunjung teraktualisasinya kesetaraan dan keadilan sosial. Feminisme merupakan suatu kajian yang memiliki wiliyah yang luas tentang kehidupan sosial pada masyarkat yang cenderung bergantung pada pemahaman atas agama dan budaya. Secara historis, feminisme merupakan upaya mewujudkan keadilan bagi kemanusiaan yang berpusat pada perempuan. Isu-isu mengenai perempuan di dalam pemahaman feminisme, sesungguhnya bukanlah gagasan baru namun tidak bisa juga dikatakan sebagai ide yang telah 
ada pada awal perkembangan teori sosial. Teori feminisme lahir dari perpecahan sosial yang turut memberi sumbangsi terhadap modernitas dan dunia akademis Barat sejak tahun 60an, dimana masyarakat wajib mereformasi pemahamannya akan konsep gender dan juga merubah tuntutan-tuntutan berdasarkan urgensi dalam kehidupan kaum perempuan yang lebih berkeadilan.

\section{Tujuan dan Manfaat :}

Tujuan dan manfaat penulisan ini adalah untuk memberi kesadaran penuh atas buruknya praksis kronis seperti perbedaan perlakuan terhadap kaum feminis serta menyatakan keadilan dalam perbedaan gender, sebab memberikan ruang bagi kaum feminis dan memberi perlakuan secara adil. Dampak dari segala upaya untuk merealisasikan kesetaraan gender ialah terwujudnya kehidupan yang adil, harmonis dan setara dalam kehidupan yang dinamis atau progresif sebagai suatu mandat dari keadilan sosial yang bersifat absolut.

\section{Pembahasan :}

Dalam Kamus Besar Bahasa Indonesia, feminisme diartikan sebagai gerakan wanita yang menuntut persamaan hak sepenuhnya antara kaum wanita dan pria yang merupakan penggabungan dari pelbagai doktrin atas hak kesetaraan. Feminisme muncul karena dilatar belakangi oleh ketimpangan relasi antara laki-laki dan perempuan dalam tatanan masyarakat sehingga pada akhirnya timbul kesadaran dan upaya untuk menghilangkan ketidakberimbangan relasi tersebut. Pada praktek keseharian istilah feminisme sering disalahpahami hanya sebagai tuntutan emansipasi kaum perempuan, padahal pada sejatinya yang dimaksud dengan istilah ini mengacu pada gerakan sosial yang dilakukan baik oleh kaum perempuan serta memperjuangkan hak-hak yang dimiliki oleh keduanya secara adil.

Berkaitan dengan itu, muncullah istilah equal right's movement atau gerakan persamaan hak, suatu upaya untuk membebaskan perempuan dari ikatan lingkungan domestic atau lingkungan keluarga dan rumah tangga. Cara tersebut sering dinamakan women's liberation movement yang disingkat women's lib atau women's emancipation movement yang merupakan implementasi dari kesadaran untuk menciptakan keadilan gender dalam kerangka demokratisasi dan Hak Asasi Manusia. Gerakan ini muncul seiring dengan ideology aufklarung yang muncul di Eropa antara akhir abad ke 14 hingga abad ke 18. Gagasan yang dominan pada waktu itu adalah 
paham rasionalisme yang ditandai dengan pemujaan akal, pikiran dan rasio. Ide rasionalisme mempengaruhi lahirnya revolusi Prancis yang menggunakan slogan kebebasan dari penindasan (liberte), pengakuan terhadap persamaan hak (egalite) dan semangat persaudaraan (fraternite) sebagai semboyan untuk meruntuhkan rezim kerajaan republi yang menggunakan sistem demokrasi ${ }^{1}$.

Berbicara mengenai status feminis dalam masyarakat, lingkungan masyarakat tradisional sampai sekarang, cenderung melihat status lebih rendah daripada laki-laki. Kaum perempuan disebut sebagai orang lemah dalam segala hal, sedangkan laki-laki adalah orang yang kuat serta memiliki kelebihan yang luar biasa. Hal itu juga mengarah pada perbedaan tugas dari laki-laki dengan perempuan di dalam rumah tangga ${ }^{2}$ Di dalam Hak Asasi Manusia, di tegaskan bahwa seharusnya tidak ada perbedaan antara hak asasi laki-laki dan hak asasi perempuan. Keduanya mempunyai hak asasi untuk hidup bermartabat, hak untuk hidup berkomunitas, hak untuk mengelolah alam ciptaan dan hak untuk membangun masa depan yang lebih baik dengan segala kewajiban asasi yang terkait.

Problematika kehidupan manusia hari-hari ini yang pada umumnya bergantung pada pemahaman atas agama dan budaya seiring perkembangan teknologi informasi tidak dapat dihadapi hanya dengan khazanah dogma agama saja. Mau tidak mau kaum agamawan harus mengakomodasi dan menggunakan berbagai metode pada jaman suara hati serta nurani individu secara kreatif demi mewacanakan solusi-solusi kesepahaman dengan mtode-metode sederhana dalam penyelesaian perbedaan atau konflik. Para agamawan, baik teolog, guru, rohaniawan, pelayan dan pemerhati gereja patut melatih kemampuan dan daya intuisi, demi menghindarkan mereka dari sikap defensif berlebihan, sehingga mereka dapat memilah serta mengambil keputusan $^{3}$ secara fleksibel atau tidak kaku dalam pengambilan keputusan, daya intuisi sebagai supralogika dapat membantu kita untuk lebih memahami feminisme lebih baik, dimana dengan daya intuisi sebagai supralogika melepaskan kita dari keterikatan ajaran resmi, membentuk suatu

\footnotetext{
${ }^{1}$ Nuril Hidayati, "Teori Feminisme: Sejarah, Perkembangan dan Relevansinya dengan Kajian Keislaman Kontemporer," BIA': Jurnal Harkat: Media Komunikasi Gender, 14 (1), 2018, http://journal.uinjkt.ac.id/index.php/psga

2 Rannu Sanderan, "Jabatan Gerejawi dan Peran Perempuan Dalam Pelayanan Gereja," BIA': Jurnal Teologi dan Pendidikan Kristen Kontekstual 3, no 2 (Desember 19, 2020) 7, https://osf.io/jtcag/

${ }^{3}$ Rannu Sanderan, “INTUISI: Pendalaman Gagasan Hans-George Gadamer tentang intuisi sebagai supralogika” BIA”: Jurnal IImiah Reliosity Entity Humanity 2, no 2 (Desember, 2020), https://ojs-jireh.org/index.php/jireh
} 
individu yang lebih kreatif serta menyadarkan kita atas praksis buruk yang telah lama membudaya, seperti diskriminasi kaum feminis, sehingga cakupan ruang bagi kaum feminis semakin luas dan keadilan dalam kesetaraan gender dapat teraktualisasi.

Kaum feminis sejatinya membutuhkan sayap, yang berarti sebagai pelindung, yang bisa melindungi. Tokoh kaum feminis di dalam Alkitab salah satunya ialah Rut, dimana ia membutuhkan Boas sebagai sayap nya. Makna pertama dari sayap diibaratkan dengan kasih dan perlindungan Allah. Artinya, berada di bawah sayapNya berarti berada di tempat perlindungan dan persekutuan dengan Tuhan. Pemazmur sendiri menggambarkan sayap Allah sebagai tempat aman atau tempat penyegaran. Pada tempat lain, sayap juga digambarkan sebagai tempat pertolongan dan peristirahatan, juga digambarkan berupa tempat yang tenang di tengah badai ${ }^{4}$.

\section{Kesimpulan dan Saran :}

Praksis diskriminasi kaum feminis yang masih berkelanjutan di sebagian ruang kendatipun wujudnya tidak begitu konkrit seperti dahulu tetapi mesti kita tinjau dengan pertimbangan nalar yang kritis agar supaya kita sadar akan buruknya tindakan perbedaan perlakuan atau ketidaksetaraan gender. Upaya untuk meruntuhkan hegemoni patriarki mesti tetap harus diperjuangkan dalam upaya untuk mengembalikan serta mewujudkan terealisasinya hak kaum feminis dan juga mewujudkan keadilan sosial dan hidup di dalam keakraban sebagai makhluk ciptaan tanpa mempertimbangkan perbedaan gender.

\footnotetext{
${ }^{4}$ Rannu Sanderan dan Yohanes Krismantyo Susanta, "Pemahaman Tentang Sayap Dalam Kitab Rut: Studi Kritik Naratif", BIA' Kamasean: Jurnal Teologi Kristen 2, no 1 (Juni:202) 47-58, http://kamasean.iakntoraja.ac.id/index.php/ojsdatakamasean/article/view/33
} 